\title{
Comparison of three trap types in sampling saproxylic beetles living in hollow urban trees
}

\author{
Elina Peuhu ${ }^{1}$ (D) $\cdot$ Pia-Maria Thomssen ${ }^{1} \cdot$ Juha Siitonen $^{2}$ (I)
}

Received: 13 July 2018 / Accepted: 28 November 2018 / Published online: 8 December 2018

(c) The Author(s) 2018

\begin{abstract}
Hollow trees are an important habitat for a large number of saproxylic invertebrates, many of which are rare or threatened. Large old trees occur frequently in cities, but the saproxylic fauna inhabiting these trees has been poorly studied. Sampling in urban areas includes the risk of trap failure due to human interference, which needs to be considered when designing sampling. The aim of our study was to find an efficient trap type for sampling saproxylic beetles in hollow urban trees. We compared the species richness and species composition of saproxylic beetle assemblages between trunk window, aluminium foil tray and pitfall traps placed inside hollow trees in the Helsinki metropolitan area, Finland. A total of 30 traps of each trap type were set in 15 trees. The traps caught a total of 4004 saproxylic beetle individuals belonging to 131 species. Trunk window and aluminium foil traps had similar assemblage and trapping efficiency, and were significantly more efficient than pitfall traps. However, pitfall traps caught certain species more efficiently than the other two trap types. Time spent separating insects from samples was the most laborious work stage. The time increased with increasing sample weight, i.e. the amount of wood mould in the trap. Trunk windows were the most efficient trap type also in terms of saproxylic species and individuals per handling time. We conclude that saproxylic beetle fauna living in hollow urban trees can be efficiently sampled with small trunk window traps or containers placed on the inner walls of hollows.
\end{abstract}

Keywords Saproxylic Coleoptera $\cdot$ Tree cavities $\cdot$ Urban parks $\cdot$ Trunk window traps $\cdot$ Pitfall traps $\cdot$ Aluminium foil traps

\section{Introduction}

Hollow trees are an important habitat for a large number of saproxylic invertebrates. Many are strict habitat specialists living only in tree cavities (Speight 1989; Siitonen 2012a). Decaying wood regularly occurs in mature living trees as heartwood decay caused by heart rot fungi. Cavity formation and hollowing are normal life cycle stages for nearly all long-lived deciduous trees such as oak (Quercus spp.) and lime (Tilia spp.) (Schwarze et al. 2000; Alexander 2008). Numerous cavity-dwelling saproxylic species have become threatened (Speight 1989; Nieto and Alexander 2010) because the number of large old trees has decreased and

Elina Peuhu

elina.peuhu@helsinki.fi

1 Department of Forest Sciences, University of Helsinki, PO Box 27, 00014 Helsinki, Finland

2 Natural Resources Institute Finland (Luke), Latokartanonkaari 9, 00790 Helsinki, Finland continues to decline, both in Europe and globally (Gibbons et al. 2008; Lindenmayer et al. 2012).

In most regions of Europe, old hollow trees occur mainly in various semi-natural habitats created and maintained by human activity, including pasture woodlands, hedgerows, avenues and parks (Oleksa et al. 2006; Dubois et al. 2009; Siitonen 2012b; Hartel et al. 2013). For example, the basal area of large $(>40 \mathrm{~cm})$ trees is approximately three times greater in old manor parks in Estonia compared to mature forest patches in the surrounding landscape, and the proportion of broadleaved trees (Tilia spp., Quercus robur and Fraxinus excelsior) is also ca. three times greater than in the forests (Lõhmus and Liira 2013). Mature hollow trees can also be found in cities. As urban areas continue to expand, valuable habitat patches containing old trees may become surrounded by built-up environments. Even more importantly, most major cities maintain large tree populations (in the order of tens to hundreds of thousands of trees per city) by actively planting and tending trees in parks and along streets (Nowak et al. 2001; Sjöman et al. 2012). Some of these trees are sufficiently old to contain hollows. 
Surveys of saproxylic beetles and dipterans in old parks in Central Europe (Franc 1997), Britain (Denton and Chandler 2005) and Northern Europe (Andersson 1999; Jonsell 2004, 2012; Sverdrup-Thygeson et al. 2010) have shown that rare and threatened species frequently occur in such habitats. In Britain, saproxylic beetle fauna in landscape parks that include relic trees are strikingly richer than fauna in parks without such continuity (Harding and Alexander 1994; Alexander 1998). However, man-made parks with mainly planted trees can also be important if they contain certain natural elements, if they are located close to potential source areas or if they are old enough (Siitonen 2012b). Hollow lime trees in old manor parks in southern Sweden host as many specialist and red-listed saproxylic beetle species as similar trees in open wood pastures or overgrown former wood pastures (Jonsell 2012). Despite hollow trees being valuable for biodiversity, urban hollow trees have received less attention. Thus, more knowledge on the conservation value of hollow trees in urban areas is needed, and such information can be used to guide management procedures and decisions.

Quantitative sampling methods with known performance are needed for studying insect assemblages living in hollows. Sampling of invertebrate is usually carried out using traps or other methods especially designed for catching certain group of species (Leather 2005; Bouget and Nageleisen 2009). Window traps (Siitonen 1994; Bouget et al. 2008), trunk window traps (Kaila 1993; Sverdrup-Thygeson et al. 2009) and emergence or eclector traps (Lindhe and Lindelöw 2004) are the methods used the most for sampling saproxylic beetles. Special methods have been developed for surveying species living in tree hollows, including pitfall traps buried in the wood mould (Ranius and Jansson 2002), emergence traps closing the cavity opening (Gouix and Brustel 2011) and even vacuum cleaning of insect fragments from the bottom of deep cavities (Bußler and Müller 2014).

Several previous papers have compared the efficiency of various sampling methods in sampling saproxylic beetles (Siitonen 1994; Økland 1996; Wikars et al. 2005; Hyvärinen et al. 2006; Alinvi et al. 2007). However, we are aware of only two previous studies that have compared the efficiency of various methods in surveying saproxylic beetle assemblages living in tree hollows (Ranius and Jansson 2002; Quinto et al. 2013). Some of the methods used in these and other studies (large window traps set outside tree hollows, emergence traps covering entire hollows) are clearly not suitable for studying trees in an urban environment. The high probability of vandalism directed at research equipment (Clarin et al. 2014) must be taken into account, especially when designing sampling in an urban environment. Hence, sampling any arthropod group in urban trees requires the adaptation of existing methodologies to suit these particular circumstances (Waite et al. 2012). Trap efficiency can be measured as numbers of individuals and species caught per trap. In addition, costs should be included in the evaluation and comparison of trapping efficiency between trap types. The costs consist of materials and trap construction, time required for setting and emptying the traps, and time needed for processing the samples (Alinvi et al. 2007).

The aim of our study was to compare the efficiency of three sampling methods-trunk window, aluminium foil tray and pitfall traps-in surveying saproxylic beetles in hollow urban trees. We addressed the following questions: (1) Which trap type is most efficient at catching saproxylic species and individuals? (2) Does species composition differ between trap types? Are certain species caught more efficiently or exclusively with a certain trap type? (3) Does the ranking of the trap types change if the time required for processing the samples in a laboratory is taken into account?

\section{Materials and methods}

The study was conducted in the Helsinki metropolitan area, Finland. The study area lies close to the northern border of the hemiboreal zone (Ahti et al. 1968). Three parks, which were known to have at least a few dozen of large, hollow deciduous trees were chosen for the study: the graveyard of St. Lawrence Church in Vantaa, and Tullisaari park and Herttoniemi manor park in Helsinki. Size of the parks varied from 14 to 20 ha. The total number of broadleaved trees $(\geq 30 \mathrm{~cm} \mathrm{DBH})$ in the three parks and their nearby surroundings varied from approximately 200 to 300 (unpublished data by the authors). Five to twelve per cent of the measured trees were hollow. Five trees with relatively large hollows (Table 1) were randomly selected from each park for trap comparison. Of these, 12 were limes (Tilia $\mathrm{x}$ vulgaris), two were Norway maples (Acer platanoides) and one was a pedunculate oak (Quercus robur). The hollow opening had to be at a height of less than two metres, the size of the hollow and the entrance hole had to be sufficiently large for setting the traps and the wood mould layer had to be reachable.

Three trap types were chosen and designed for the study: trunk window, aluminium foil and pitfall traps (Fig. 1). They were small enough to fit inside the hollows, known to catch saproxylic beetles relatively well and were quite inconspicuous, which is an important feature in urban areas due to the potential vandalism that traps

Table 1 Variables describing the sampling trees and their hollows

\begin{tabular}{llc}
\hline Variables & $\begin{array}{l}\text { Mean } \pm \text { stand- } \\
\text { ard error }\end{array}$ & Range \\
\hline Tree diameter at breast height $(\mathrm{cm})$ & $99 \pm 21$ & $54-137$ \\
Size of entrance hole $\left(\mathrm{dm}^{2}\right)$ & $31 \pm 23$ & $5-85$ \\
Height from ground to entrance hole $(\mathrm{cm})$ & $90 \pm 55$ & $0-165$ \\
\hline
\end{tabular}




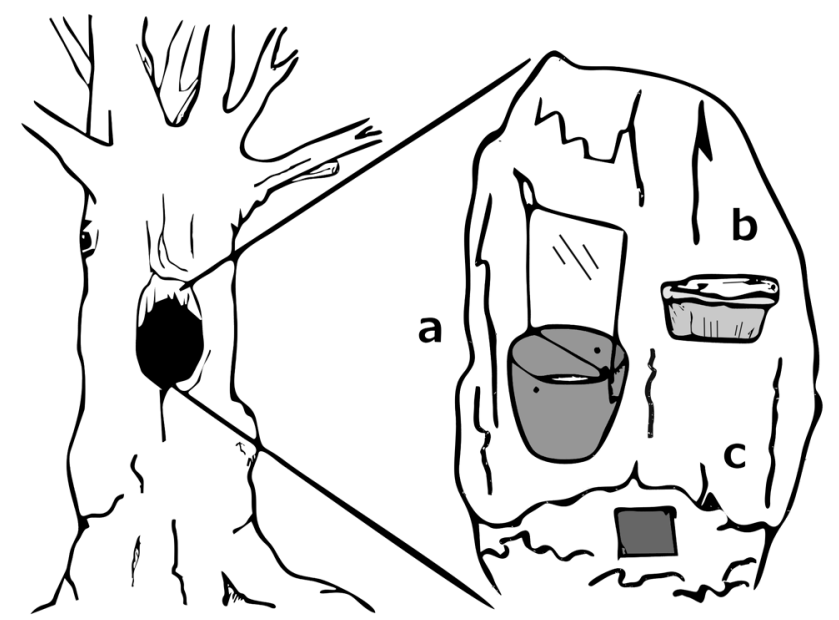

Fig. 1 Placement inside a tree hollow of the three trap types used in the study: $a$ trunk window trap, $b$ aluminium foil trap and $c$ pitfall trap (only the lid is shown)

may encounter. Two traps of each trap type were placed inside each sampling tree, making a total of 90 traps. The six traps in each tree were situated within the same hollow so that they were relatively easy to set up and empty and more or less undetectable from the outside.

The trunk window traps were round anthracite-coloured plastic jars with a mouth diameter of $13.5 \mathrm{~cm}$ and a height of $12.5 \mathrm{~cm}$. A transparent polycarbonate plastic panel $(15 \times 15 \mathrm{~cm}, 1 \mathrm{~mm}$ thick) was attached above the jar for flight interception. The trap was hung on a nail on the inner wall of the hollow (Fig. 1). The aluminium foil traps were half-litre trays (length $13 \mathrm{~cm}$, width $10.5 \mathrm{~cm}$, height $3.7 \mathrm{~cm}$ ). They were pinned to the wall with drawing pins and shaped to adjust to the inner surface of the hollow. The pitfall traps were plastic transparent jars with a mouth diameter of $7 \mathrm{~cm}$ and a height of $7 \mathrm{~cm}$. They were buried at mouth-level into the wood mould inside the hollow. A brown plastic lid $(10 \times 10 \mathrm{~cm})$, supported by a metal rod bent through its two corners, was placed two centimetres above the jar to prevent litter and wood mould from falling into the jar. The material costs of the aluminium foil and pitfall traps were approximately one euro each, while the trunk window traps cost ca. five euros each. All traps were two-thirds filled with ethylene glycol diluted to $10 \%$ to preserve the insects; a few drops of detergent were added to eliminate surface tension. The traps were emptied every three weeks from May 30th to September 9th (the graveyard of St. Lawrence Church and Tullisaari park) or from May 26th to September 8th (Herttoniemi manor park) in 2006, totalling 450 samples ( 90 traps $\times 5$ emptying periods). The total time (in hours) required for setting and emptying the traps was estimated afterwards.
All beetles were separated from the samples and identified to species level. The time spent separating invertebrates (Coleoptera, Hymenoptera, Diptera and Pseudoscorpionida) from the samples in a laboratory was measured to the accuracy of five minutes. The samples mainly consisted of wood mould, wood particles and litter. Sample weight was measured to the accuracy of one gram. The samples were stored in $1.5 \mathrm{dl}$ plastic screw-top jars in $75 \%$ ethanol. Before weighing, each sample was taken from the jar and left to drain for approximately half a minute. The weight and handling time were measured from a total of 301 samples, including 88 trunk window, 105 aluminium foil and 108 pitfall trap samples. Total times (in hours) required for separating invertebrates from the samples and determining the beetles to the species level were calculated.

\section{Data analyses}

Beetles were classified into two groups based on their ecology: saproxylic and non-saproxylic species. The classification of species was based on literature (mainly Palm 1951, 1959; Koch 1989-1995) and our own expertise. The red-list statuses for the species, according to the IUCN categories in Finland, were obtained from Rassi et al. (2010). The nomenclature follows Rassi et al. (2015).

Both missing samples (trap missing or displaced) and empty samples (no beetles) were treated as null values in the beetle data and included in the analyses. Missing samples account for a part of trapping efficiency in practice. In urban areas vandalism may affect different trap types differently, and it is one of the factors affecting the total catch when applying a given sampling effort. Thus the missing samples were included in the data analysis as null values. In each tree, beetle samples from the two traps of the same trap type were pooled to minimize the effect of random variation originating from trap placement. Beetle samples from the different sampling periods were also pooled. Thus the sample size per trap type was $n=15$.

Because the beetle data were not normally distributed, non-parametric tests were used for the analyses. Friedman non-parametric test for randomized complete block design was used for analysing differences in the numbers of saproxylic and non-saproxylic species and individuals between the three trap types. The numbers of saproxylic species and individuals varied considerably between the 15 sampling trees, thus each tree was considered a random effect (block) in the testing for minimizing the effect of the uninteresting factor. The Nemenyi test was used as a post hoc test for the Friedman's test to investigate which trap types differed significantly from each other. Differences in the numbers of individuals between the trap types were also analysed for the families and individual species of which at least ten individuals were caught. Friedman's test and Dunn's test with 
Bonferroni correction as a post hoc test were used to detect significant differences between the trap types.

The similarity of the species assemblage in the three trap types was visualized with Non-metric Multidimensional Scaling (NMDS) ordination based on the Bray-Curtis similarity index (McCune et al. 2002). The statistical difference of the three assemblages was tested with the multi-response permutation procedure of within-group versus among-group dissimilarities (mrpp) using the dissimilarity index "Bray" (McCune et al. 2002).

Differences in sample weights, time spent separating insects from the samples and numbers of beetle species and individuals per sample between the three trap types were analysed with the Kruskal-Wallis test. Four of the largest observations (two from trunk windows and two from aluminium foil traps) with high leverage were removed from the data, resulting in a sample size of $n=297$. For post hoc testing we used the Nemenyi test. To assess how sample weight, total number of beetle individuals in the sample and trap type affect the time spent handling a sample, a linear model (LM) was applied. The efficiency of a trap type also depends on how much time is required for handling the samples; this efficiency can be measured as species recorded per time unit. Thus, we applied a linear model to test how the number of saproxylic beetle species handled per minute depends on sample weight and trap type. All statistical tests were performed with open source programme $\mathrm{R}$ version 3.3.2. ( $\mathrm{R}$ Development Core Team 2008).

\section{Results}

The traps caught a total of 4695 beetle individuals belonging to 255 species and 46 families. Of these, 4004 individuals (85\%) and 131 species ( $51 \%$ ) belonging to 36 families were saproxylic. Three species, Eucnemis capucina Ahrens, 1812, Mycetochara axillaris (Paykull, 1799) and Phloeophagus turbatus Schönherr, 1845, made up $40 \%$ of the saproxylic individuals. Five species, Euconnus pragensis (Machulka, 1923), Quedius microps Gravenhorst, 1847, E. capucina, Cryptophagus fuscicornis Sturm, 1845 and Eledona agricola (Herbst, 1783), are classified as near threatened (IUCN category NT) in Finland (Rassi et al. 2010).

We caught significantly lower numbers of saproxylic species and individuals in pitfalls than in the other two trap types (Table 2; Fig. 2). The average number of saproxylic species was 19.8 in the trunk windows, 18.7 in the aluminium foil and 11.8 in the pitfall traps. Contrastingly, the average number of non-saproxylic beetles was approximately the same in all trap types, and pitfalls caught more (though not significantly so) non-saproxylic individuals than the other two trap types (Table 2; Fig. 2). The number of saproxylic beetle species caught varied considerably between the individual sampling trees. However, the trap types appeared to work in approximately the same way in the different trees, i.e. species-rich trees had generally more species in all trap types than species-poor trees (Fig. 3).

We observed 38 saproxylic species (of which 31 were singletons) in only one of the trap types: 17 in window, 14 in aluminium foil and seven in pitfall traps. The respective numbers of individuals were 18, 21 and 32. Only one of the species (Oxypoda vittata) had more than four (24) individuals. The three trap types shared 51 saproxylic species.
Table 2 Total numbers of species and individuals in each trap type

\begin{tabular}{|c|c|c|c|c|c|c|}
\hline & \multicolumn{3}{|c|}{ Trap type } & \multirow[t]{2}{*}{ Total } & \multicolumn{2}{|c|}{ Friedman test } \\
\hline & TW & $\mathrm{AF}$ & $\mathrm{PF}$ & & $\mathrm{X}^{2}$ & $p$ \\
\hline \multicolumn{7}{|l|}{ Species } \\
\hline Saproxylic & $104 \mathbf{a}$ & $101 \mathbf{a}$ & $70 \mathbf{b}$ & 131 & 12.5 & 0.002 \\
\hline Non-saproxylic & 66 & 61 & 66 & 124 & 1.8 & 0.410 \\
\hline \multicolumn{7}{|l|}{ Individuals } \\
\hline Saproxylic & $1948 \mathbf{a}$ & $1489 \mathbf{a}$ & $567 \mathrm{~b}$ & 4004 & 15.6 & $<\mathbf{0 . 0 0 0}$ \\
\hline Non-saproxylic & 217 & 165 & 309 & 691 & 1.1 & 0.575 \\
\hline \multicolumn{7}{|l|}{ Samples } \\
\hline Empty & 16 & 18 & 30 & 64 & & \\
\hline Missing & 8 & 3 & 3 & 14 & & \\
\hline
\end{tabular}

Significant differences between trap types (based on Nemenyi post hoc test) are indicated in bold and with different letters. Note that testing is not based on the total numbers of species or individuals, but on the numbers of species or individuals per trap $(n=15$ in each trap type) given in Fig. 2. Numbers of empty (no beetles) or missing (trap lost) samples in each trap type (out of the total of 450 samples) are given in the lower part of the table

$T W$ trunk window trap, $A F$ aluminium foil trap, $P F$ pitfall trap 


\section{Saproxylic}
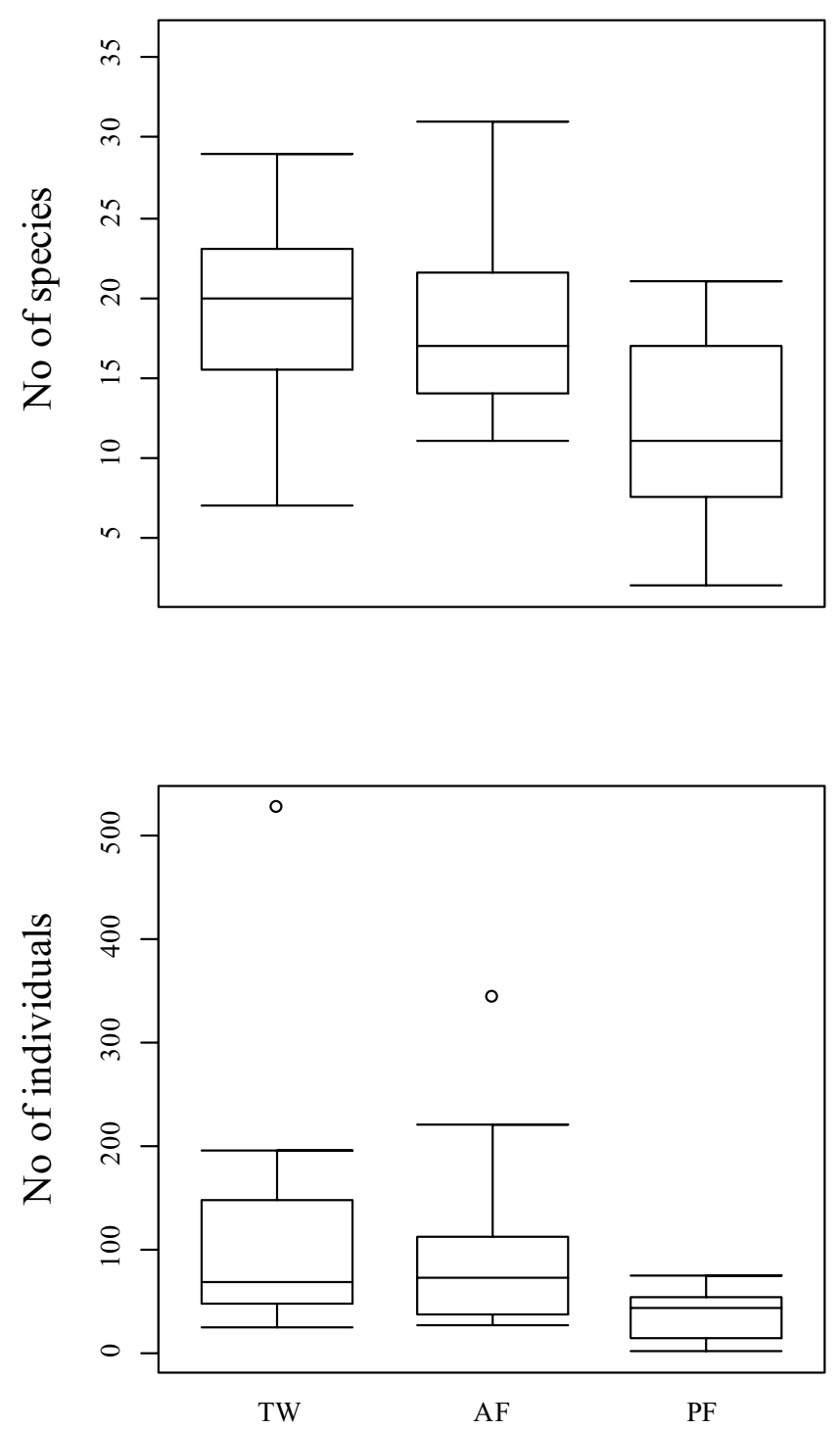

Fig. 2 Median, lower and upper quartiles of the number of saproxylic and non-saproxylic beetle species and individuals in the studied three trap types. Upper whiskers represent the 75 th upper percentile +1.5

Of the beetle families with at least ten observed individuals (all individuals of saproxylic species belonging to the pooled family), five families had significantly more individuals in trunk window traps and three families in aluminium foil traps than in pitfall traps (Table 3). Pitfall traps did not catch any of the families more efficiently than the other two trap types. Of those saproxylic beetle species that had at least ten individuals, eight species had significantly more individuals in trunk window traps and five in aluminium foil traps than in pitfall traps, whereas three species were significantly more abundant in pitfall traps than in either of the other two trap types (Table 4).
Non-saproxylic
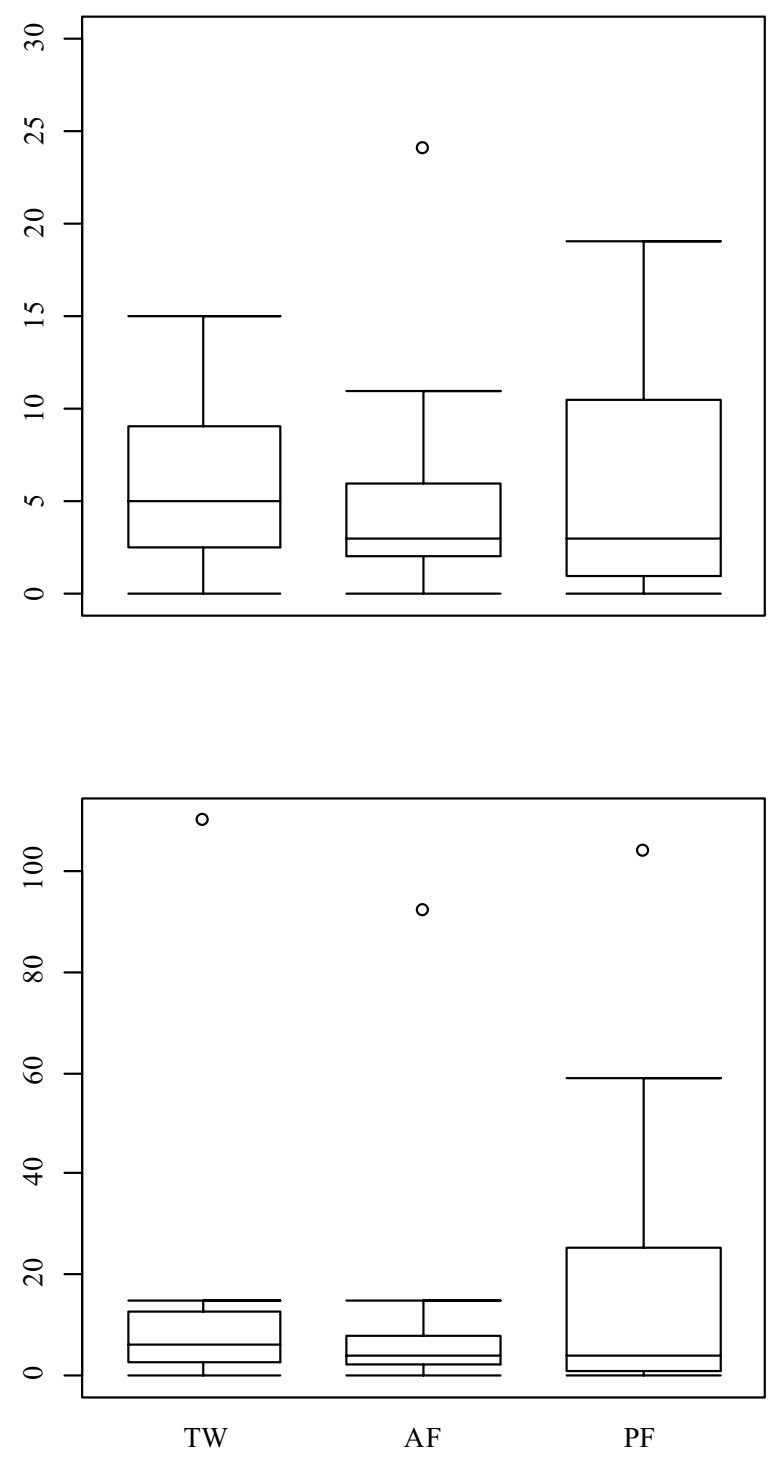

* interquartile length (IQL) and lower whiskers the 25th percentile $1.5 *$ IQL. $T W$ trunk window trap, $A F$ aluminium foil trap, $P F$ pitfall trap ( $\mathrm{n}=15$ in each trap type)

Trunk window and aluminium foil traps had very similar species assemblages (Fig. 4). Variation in species composition was larger in trunk window than in aluminium foil traps. Species composition in pitfall traps differed clearly from species composition in the other two trap types.

We found no Coleoptera in 64 samples (Table 2), 48 of which were from the last two periods from the end of July to the beginning of September. Most samples with no beetles were from pitfalls (30). In addition, a total of 14 samples were missing because a trap was lost or displaced during the sampling period. 
Fig. 3 The number of saproxylic species in individual trees in the three trap types. Sampling trees in each park are arranged from least species-rich to most species-rich

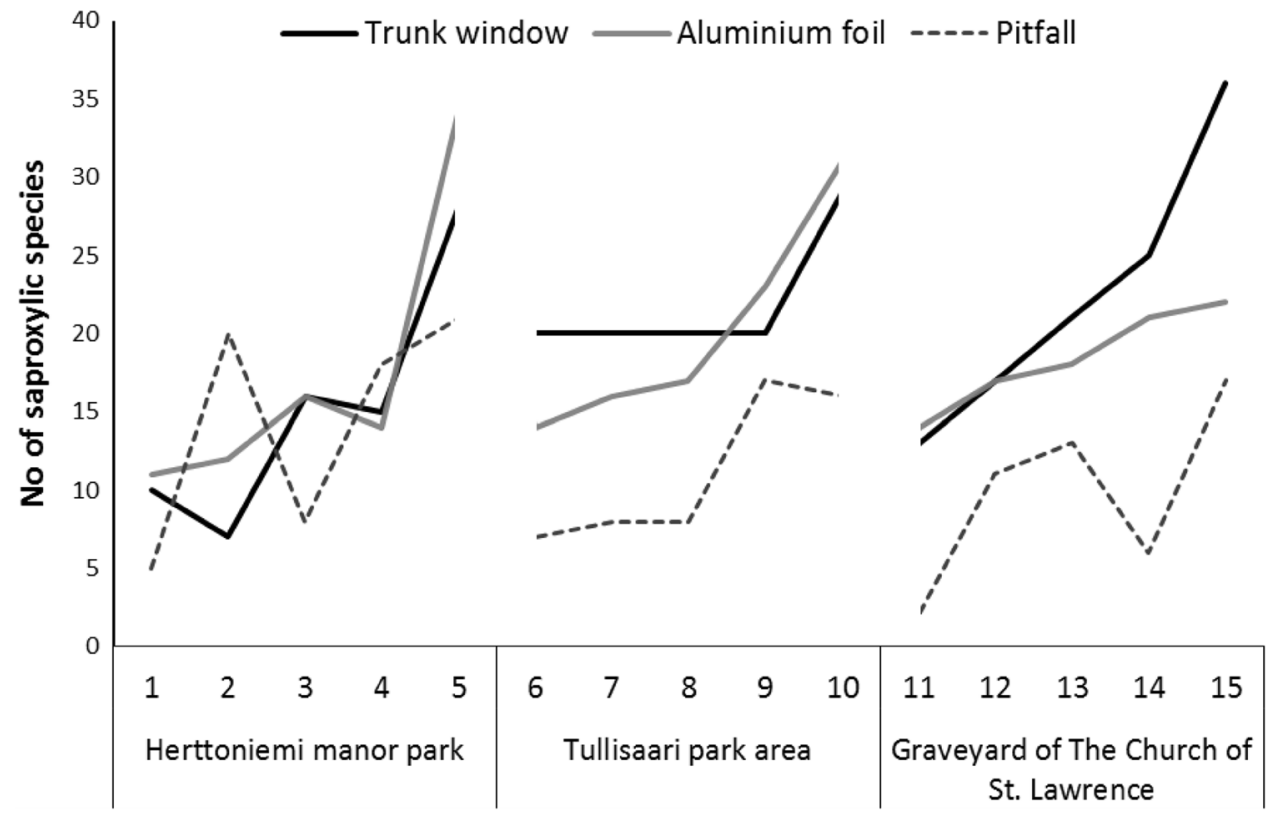

Pitfalls had the lightest samples, and the average time spent separating insects from these samples was also the shortest (Table 5). In terms of saproxylic species and individuals per sample, trunk window traps were the most efficient and had twice as many species and four times as many individuals per sample than pitfall traps. Aluminium foil traps were intermediate in their efficiency. In terms of sample handling time, trunk window traps yielded nearly twice as many saproxylic species per minute than pitfall traps; however, the difference was not significant (Table 5). Trunk windows yielded nearly three times as many saproxylic individuals per minute than pitfall traps, and this difference was significant (Table 5). Aluminium foil traps were once again intermediate in their efficiency.

Sample weight explained most of the variation in handling time in the linear model (intercept 8.5, coefficient 1.5, $\mathrm{p}<0.001$ ) (Fig. 5a). When the total number of beetle individuals and trap type were included in the model, beetle individuals had a significant but minor effect on handling time (coefficient $=0.3, \mathrm{p}<0.001$ ). Trap type also had a significant effect on handling time (aluminium foil traps compared to trunk windows: coefficient 7.2, $\mathrm{p}=0.01$; pitfalls compared to trunk windows: coefficient $-0.9, \mathrm{p}=0.8, \mathrm{~ns}$ ).

Sample weight did not have a significant effect on the number of saproxylic species recorded per minute (intercept $=0.1$, coefficient $=-0.0005, p=0.208$ ). However, we observed a tendency where the heaviest samples were less efficient than the lighter ones (Fig. 5b). When we included trap type into the model, pitfall traps were significantly less efficient than trunk window traps (coefficient $=-0.05$, $\mathrm{p}=0.005)$. Aluminium foil traps did not differ from trunk windows (coefficient $=-0.02, p=0.192$ ).
The fieldwork, i.e. setting and emptying the traps, took a total of ca. $110 \mathrm{~h}$. Separating insects from the samples took approximately $280 \mathrm{~h}$. Identification of the beetle material took approximately $120 \mathrm{~h}$.

\section{Discussion}

\section{Trap type comparison}

Our results indicate that all the studied trap types were suitable for sampling saproxylic beetles in hollow urban trees. We caught a large number of saproxylic species with relatively low sampling effort. Furthermore, approximately $85 \%$ of all the individuals caught belonged to saproxylic species, which indicates that the traps mainly caught species living in the cavities and only a few "tourists". Regarding the individuals and species caught, trunk window and aluminium foil traps were significantly more efficient than pitfall traps. Trunk windows caught nearly $70 \%$ and aluminium foil traps nearly $60 \%$ more saproxylic species per trap than pitfall traps.

Despite obvious differences in the construction of trunk window and aluminium foil traps, our results suggest that both trap types have a similar trapping mechanism. The transparent plastic panel used as a flight intercept for catching flying individuals did not appear to have any effect on trapping efficiency. This is supported by the fact that both trap types placed in the same microhabitat (the inner wall of a hollow) caught very similar numbers and assemblages of saproxylic beetles. Thus, most of the individuals we caught have probably entered the traps by falling from the wall above the trap. In such a case, any container attached to a 
Table 3 Beetle families with at least ten saproxylic individuals caught in our study traps

\begin{tabular}{|c|c|c|c|c|c|c|c|}
\hline \multirow[t]{2}{*}{ Family } & \multirow[t]{2}{*}{ No. of species } & \multicolumn{4}{|c|}{ No. of individuals } & \multicolumn{2}{|c|}{ Friedman test } \\
\hline & & TW & $\mathrm{AF}$ & $\mathrm{PF}$ & Total & $\mathrm{X}^{2}$ & $p$ \\
\hline Histeridae & 1 & 4 & 6 & 11 & 21 & 2.8 & 0.247 \\
\hline Leiodidae & 4 & 33 & 27 & 6 & 66 & 1.4 & 0.495 \\
\hline Scydmaenidae & 6 & 4 & 10 & 3 & 17 & 4.4 & 0.112 \\
\hline Staphylinidae & 26 & 268 & 166 & 197 & 631 & 1.8 & 0.408 \\
\hline Trogidae & 1 & 0 & 2 & 9 & 11 & 3.7 & 0.156 \\
\hline Eucnemidae & 1 & $232 \mathbf{a}$ & $173 \mathbf{a}$ & $46 \mathbf{a}$ & 451 & 6.4 & 0.042 \\
\hline Elateridae & 8 & 21 & 21 & 10 & 52 & 4.4 & 0.109 \\
\hline Cantharidae & 6 & 20 & 17 & 7 & 44 & 5.2 & 0.076 \\
\hline Dermestidae & 2 & $14 \mathbf{a}$ & $8 \mathbf{a}$ & $0 \mathbf{b}$ & 22 & 7.8 & 0.021 \\
\hline Anobiidae & 9 & $102 \mathbf{a}$ & $56 \mathbf{a b}$ & $17 \mathbf{b}$ & 175 & 11.4 & 0.003 \\
\hline Trogossitidae & 2 & 5 & 16 & 3 & 24 & 1.6 & 0.449 \\
\hline Sphindidae & 2 & 21 & 35 & 3 & 59 & 5.4 & 0.068 \\
\hline Monotomidae & 4 & 4 & 8 & 48 & 60 & 4.2 & 0.125 \\
\hline Cryptophagidae & 5 & 24 & 18 & 70 & 112 & 3.0 & 0.226 \\
\hline Erotylidae & 3 & 15 & 56 & 5 & 76 & 5.8 & 0.056 \\
\hline Cerylonidae & 3 & 34 & 29 & 8 & 71 & 1.1 & 0.575 \\
\hline Latridiidae & 8 & 51 & 45 & 39 & 135 & 5.1 & 0.080 \\
\hline Mycetophagidae & 3 & 10 & 40 & 2 & 52 & 5.1 & 0.080 \\
\hline Ciidae & 4 & 145 & 47 & 1 & 193 & 2.9 & 0.232 \\
\hline Tetratomidae & 1 & 10 & 2 & 0 & 12 & 2.0 & 0.368 \\
\hline Tenebrionidae & 6 & $566 \mathbf{a}$ & $283 \mathbf{a}$ & $13 \mathbf{b}$ & 862 & 23.3 & $<0.001$ \\
\hline Aderidae & 2 & 5 & 4 & 1 & 10 & 2.0 & 0.368 \\
\hline Scraptiidae & 3 & $47 \mathbf{a}$ & $45 \mathbf{a}$ & $4 \mathbf{b}$ & 96 & 18.3 & $<0.001$ \\
\hline Cerambycidae & 1 & 27 & 48 & 1 & 76 & 5.2 & 0.074 \\
\hline Curculionidae & 7 & $274 \mathbf{a}$ & $317 \mathbf{a b}$ & $61 b$ & 652 & 14.5 & 0.001 \\
\hline
\end{tabular}

The numbers of species and individuals in each trap type and in total are shown. Results of Friedman nonparametric test of randomized complete block design (Chi square test statistics and p-value) are given. Families with significant $(p \leq 0.05)$ differences between trap types (post hoc Dunnś test with Bonferroni correction) are indicated in bold, and trap types differing significantly from each other with different letters. Note that testing is not based on the total numbers of individuals, but on the numbers of individuals per trap $(\mathrm{n}=15)$

$T W$ trunk window trap, $A F$ aluminium foil trap, $P F$ pitfall trap cavity wall and filled with liquid will function as a trap. The surface area of the container most likely affects trapping efficiency, i.e. large traps are potentially more efficient than small ones. However, hollow or cavity opening size may restrict the practical size of a trap. In addition, traps should preferably be relatively small and inconspicuous in urban areas to avoid vandalism.

Previous studies have observed trunk window traps attached directly to the trunks of dead trees to be more efficient at catching saproxylic beetles than freely hanging window traps (Hyvärinen et al. 2006), or at least at catching species associated with the particular substrate (SverdrupThygeson et al. 2009). Freely hanging window traps set in front of cavity openings are efficient in sampling saproxylic beetles living in cavities (Ranius and Jansson 2002; Jansson et al. 2009; Sverdrup-Thygeson et al. 2010; Quinto et al. 2013). Such traps resemble trunk window traps, as they are placed close to the substrate of target species, yet species trapping is based on flight interception. To our knowledge, trunk window traps placed inside hollows have not been used previously; aluminium foil traps have been used in one published inventory (Biström et al. 2000). Many cavity specialist species appear to have low dispersal propensity and most individuals may remain in their host trees (Ranius and Jansson 2002; Hedin et al. 2008; Gouix and Brustel 2011). Thus, it would be interesting to compare species composition in similar trunk window traps (or "trunk traps" without a window) placed inside cavities and just outside their openings.

Pitfall traps buried in wood mould can be expected to catch partly different species than traps attached to cavity walls. In our present material, only three species (Oxypoda vittata, Quedius mesomelinus and Cryptophagus distinguendus) were significantly more abundant in pitfall traps than in the other two trap types. However, certain 
Table 4 Saproxylic species with at least 10 individuals caught in our study traps

\begin{tabular}{|c|c|c|c|c|c|c|c|}
\hline \multirow[t]{2}{*}{ Species } & \multirow[t]{2}{*}{ No. trees } & \multicolumn{4}{|c|}{ Number of individuals } & \multicolumn{2}{|c|}{ Friedman test } \\
\hline & & TW & $\mathrm{AF}$ & $\mathrm{PF}$ & Total & $X^{2}$ & $p$ \\
\hline \multicolumn{8}{|l|}{ Histeridae } \\
\hline Gnathoncus buyssoni & 5 & $4(19 \%)$ & $6(29 \%)$ & $11(52 \%)$ & 21 & 2.8 & 0.247 \\
\hline \multicolumn{8}{|l|}{ Leiodidae } \\
\hline Anisotoma humeralis & 3 & $10(67 \%)$ & $3(20 \%)$ & $2(13 \%)$ & 15 & 2.0 & 0.368 \\
\hline A. orbicularis & 3 & $17(40 \%)$ & $23(55 \%)$ & $2(5 \%)$ & 42 & 5.6 & 0.061 \\
\hline \multicolumn{8}{|l|}{ Staphylinidae } \\
\hline Euplectus nanus & 8 & $23(50 \%)$ & $20(43 \%)$ & $3(7 \%)$ & 46 & 5.6 & 0.060 \\
\hline E. karstenii & 10 & $95(62 \%) \mathbf{a}$ & $45(29 \%) \mathbf{a}$ & $14(9 \%) \mathbf{b}$ & 154 & 12.2 & 0.002 \\
\hline Sepedophilus testaceus & 10 & $20(42 \%)$ & $17(35 \%)$ & $11(23 \%)$ & 48 & 0.2 & 0.905 \\
\hline Oxypoda vittata & 3 & $0 \mathbf{a}$ & $0 \mathbf{a}$ & $24(100 \%) \mathbf{b}$ & 24 & 6.0 & 0.050 \\
\hline Atheta nigricornis & 7 & $15(26 \%)$ & $12(21 \%)$ & $30(53 \%)$ & 57 & 1.1 & 0.568 \\
\hline Bisnius subuliformis & 5 & $1(7 \%)$ & $5(33 \%)$ & $9(60 \%)$ & 15 & 3.5 & 0.174 \\
\hline Quedius mesomelinus & 9 & $2(8 \%) \mathbf{a}$ & $1(4 \%) \mathbf{a}$ & $21(88 \%) \mathbf{b}$ & 24 & 16.3 & 0.000 \\
\hline Q. brevicornis & 10 & $43(51 \%)$ & $14(16 \%)$ & $28(33 \%)$ & 85 & 0.5 & 0.798 \\
\hline Q. microps NT & 9 & $23(35 \%)$ & $24(37 \%)$ & $18(28 \%)$ & 65 & 0.1 & 0.968 \\
\hline Q. scitus & 9 & $18(36 \%)$ & $9(18 \%)$ & $23(46 \%)$ & 50 & 1.2 & 0.542 \\
\hline \multicolumn{8}{|l|}{ Trogidae } \\
\hline Trox scaber & 2 & 0 & $2(18 \%)$ & $9(82 \%)$ & 11 & 3.7 & 0.156 \\
\hline \multicolumn{8}{|l|}{ Eucnemidae } \\
\hline Eucnemis capucina NT & 10 & $232(51 \%) \mathbf{a}$ & $173(38 \%) \mathbf{a}$ & $46(10 \%) \mathbf{a}$ & 451 & 6.4 & 0.042 \\
\hline \multicolumn{8}{|l|}{ Elateridae } \\
\hline Ampedus nigroflavus & 5 & $6(46 \%)$ & $5(38 \%)$ & $2(15 \%)$ & 13 & 1.6 & 0.444 \\
\hline A. erythrogonus & 5 & $7(44 \%)$ & $5(31 \%)$ & $4(25 \%)$ & 16 & 0.4 & 0.819 \\
\hline Melanotus castanipes & 9 & $3(23 \%)$ & $6(46 \%)$ & $4(31 \%)$ & 13 & 0.9 & 0.641 \\
\hline \multicolumn{8}{|l|}{ Cantharidae } \\
\hline Malthodes crassicornis & 6 & $14(41 \%)$ & $14(41 \%)$ & $6(18 \%)$ & 34 & 3.9 & 0.142 \\
\hline \multicolumn{8}{|l|}{ Dermestidae } \\
\hline Ctesias serra & 7 & $12(63 \%) \mathbf{a}$ & $7(37 \%) \mathbf{a}$ & $0 \mathbf{b}$ & 19 & 7.8 & 0.021 \\
\hline \multicolumn{8}{|l|}{ Anobiidae } \\
\hline Ptinus fur & 8 & $8(32 \%)$ & $10(40 \%)$ & $7(28 \%)$ & 25 & 0.6 & 0.756 \\
\hline P. subpillosus & 3 & $8(44 \%)$ & $5(28 \%)$ & $5(28 \%)$ & 18 & 3.8 & 0.150 \\
\hline Anobium rufipes & 4 & $8(50 \%) \mathbf{a}$ & $8(50 \%) \mathbf{a}$ & $0 \mathbf{a}$ & 16 & 6.5 & $\mathbf{0 . 0 3 8}$ \\
\hline Hadrobremus pertinax & 4 & $14(67 \%)$ & $5(24 \%)$ & $2(10 \%)$ & 21 & 3.8 & 0.146 \\
\hline H. confusus & 3 & $8(73 \%)$ & $3(27 \%)$ & 0 & 11 & 2.6 & 0.273 \\
\hline Dorcatoma substriata & 2 & $51(70 \%)$ & $21(29 \%)$ & $1(1 \%)$ & 73 & 3.7 & 0.156 \\
\hline \multicolumn{8}{|l|}{ Trogossitidae } \\
\hline Grynocharis oblonga & 5 & $5(22 \%)$ & $16(70 \%)$ & $2(9 \%)$ & 23 & 3.6 & 0.165 \\
\hline \multicolumn{8}{|l|}{ Sphindidae } \\
\hline Aspidiphorus orbiculatus & 4 & $21(36 \%)$ & $34(59 \%)$ & $3(5 \%)$ & 58 & 3.8 & 0.146 \\
\hline \multicolumn{8}{|l|}{ Monotomidae } \\
\hline Rhizophagus parallelocollis & 3 & $1(2 \%) \mathbf{a}$ & $1(2 \%) \mathbf{a}$ & $43(96 \%) \mathbf{a}$ & 45 & 6.0 & $\mathbf{0 . 0 5 0}$ \\
\hline \multicolumn{8}{|l|}{ Cryptophagidae } \\
\hline Cryptophagus badius & 11 & $12(21 \%)$ & $11(19 \%)$ & $34(60 \%)$ & 57 & 0.7 & 0.697 \\
\hline C. distinguendus & 7 & $0 \mathbf{a}$ & $2(7 \%) \mathbf{a}$ & $26(93 \%) \mathbf{b}$ & 28 & 13.5 & 0.001 \\
\hline Atomaria morio & 10 & $10(53 \%)$ & $4(21 \%)$ & $5(26 \%)$ & 19 & 1.6 & 0.459 \\
\hline \multicolumn{8}{|l|}{ Erotylidae } \\
\hline Dacne bipustulata & 5 & $13(19 \%)$ & $53(76 \%)$ & $4(6 \%)$ & 70 & 5.8 & 0.056 \\
\hline
\end{tabular}


Table 4 (continued)

\begin{tabular}{|c|c|c|c|c|c|c|c|}
\hline \multirow[t]{2}{*}{ Species } & \multirow[t]{2}{*}{ No. trees } & \multicolumn{4}{|c|}{ Number of individuals } & \multicolumn{2}{|c|}{ Friedman test } \\
\hline & & TW & $\mathrm{AF}$ & $\mathrm{PF}$ & Total & $X^{2}$ & $p$ \\
\hline \multicolumn{8}{|l|}{ Cerylonidae } \\
\hline Cerylon fagi & 7 & $2(14 \%)$ & $7(50 \%)$ & $5(36 \%)$ & 14 & 1.8 & 0.401 \\
\hline C. histeroides & 7 & $20(69 \%)$ & $7(24 \%)$ & $2(7 \%)$ & 29 & 3.7 & 0.154 \\
\hline C. ferrugineum & 4 & $12(43 \%)$ & $15(54 \%)$ & $1(4 \%)$ & 28 & 1.9 & 0.395 \\
\hline \multicolumn{8}{|l|}{ Latridiidae } \\
\hline Latridius hirtus & 6 & $8(28 \%)$ & $14(48 \%)$ & $24 \%(7)$ & 29 & 1.5 & 0.467 \\
\hline L. anthracinus & 9 & $7(20 \%)$ & $9(26 \%)$ & $54 \%(19)$ & 35 & 1.4 & 0.508 \\
\hline L. nidicola & 8 & $4(40 \%)$ & $4(40 \%)$ & $20 \%(2)$ & 10 & 0.6 & 0.756 \\
\hline Enicmus rugosus & 10 & $25(61 \%) \mathbf{a}$ & $12(29 \%) \mathbf{a b}$ & $4(10 \%) \mathbf{b}$ & 41 & 11.1 & 0.004 \\
\hline Dienerella elongata & 6 & $5(43 \%)$ & $3(25 \%)$ & $4(33 \%)$ & 12 & 0.1 & 0.949 \\
\hline \multicolumn{8}{|l|}{ Mycetophagidae } \\
\hline Mycetophagus quadripustulatus & 1 & $2(10 \%)$ & $19(90 \%)$ & 0 & 21 & 2.0 & 0.368 \\
\hline M. multipunctatus & 1 & $3(13 \%)$ & $19(79 \%)$ & $2(8 \%)$ & 24 & 2.0 & 0.368 \\
\hline \multicolumn{8}{|l|}{ Ciidae } \\
\hline Ennearthron cornutum & 2 & $86(74 \%)$ & $30(26 \%)$ & $1(1 \%)$ & 117 & 2.0 & 0.368 \\
\hline E. laricinum & 2 & $58(78 \%)$ & $16(22 \%)$ & 0 & 74 & 2.0 & 0.368 \\
\hline \multicolumn{8}{|l|}{ Tetratomidae } \\
\hline Hallomenus binotatus & 1 & $10(83 \%)$ & $2(17 \%)$ & 0 & 12 & 2.0 & 0.368 \\
\hline \multicolumn{8}{|l|}{ Tenebrionidae } \\
\hline Pseudocistela ceramboides & 8 & $17(63 \%) \mathbf{a}$ & $10(37 \%) \mathbf{a}$ & $0 \mathbf{b}$ & 27 & 11.6 & 0.003 \\
\hline Mycetochara axillaris & 15 & $240(49 \%) \mathbf{a}$ & $244(49 \%) \mathbf{a}$ & $10(2 \%) \mathbf{b}$ & 494 & 22.4 & $\mathbf{0 . 0 0 0}$ \\
\hline Eledona agricola $\mathrm{NT}$ & 1 & $285(92 \%)$ & $24(8 \%)$ & $2(1 \%)$ & 311 & 2.0 & 0.368 \\
\hline Diaperis boleti & 1 & $19(95 \%)$ & $1(5 \%)$ & 0 & 20 & 2.0 & 0.368 \\
\hline \multicolumn{8}{|l|}{ Scraptiidae } \\
\hline Anaspis marginicollis & 15 & $39(47 \%) \mathbf{a}$ & $40(48 \%) \mathbf{a}$ & $4(5 \%) \mathbf{b}$ & 83 & 10.7 & 0.005 \\
\hline A. rufilabris & 6 & $8(80 \%) \mathbf{a}$ & $2(20 \%) \mathbf{b}$ & $0 \mathbf{b}$ & 10 & 10.3 & 0.006 \\
\hline \multicolumn{8}{|l|}{ Cerambycidae } \\
\hline Alosterna tabacicolor & 4 & $27(36 \%)$ & $48(63 \%)$ & $1(1 \%)$ & 76 & 5.2 & 0.074 \\
\hline \multicolumn{8}{|l|}{ Curculionidae } \\
\hline Phloeophagus turbatus & 13 & $271(42 \%) \mathbf{a}$ & $314(49 \%) \mathbf{a b}$ & $61(9 \%) \mathbf{b}$ & 646 & 14.0 & 0.001 \\
\hline
\end{tabular}

If a species is mentioned on the Red List Category (IUCN) of Finnish species (Rassi et al. 2010), its status is indicated after the species names (NT near threatened). The number of trees in which the species were found, number of individuals in each trap type and the total number of individuals of each species are given. Percentages in parentheses are the proportions of individuals of each species caught in each trap type. Results of Friedman non-parametric test of randomized complete block design for differences among trap type are also given. Note that the testing is based on the numbers of individuals per trap, not on the total numbers of individuals given in the table. Species with significant $(p \leq 0.05)$ differences in numbers of individuals between trap types (post hoc Dunn's test with Bonferroni corrections) are indicated in bold, and trap types differing significantly from each other with different letters

$T W$ trunk window trap, $A F$ aluminium foil trap, $P F$ pitfall trap, $\mathrm{n}=15$ in each trap type

other staphylinid species (e.g. Bisnius subuliformis), cryptophagid species (e.g. Cryptophagus badius) and other species (e.g. Rhizophagus parallelocollis, Trox scaber) were mainly caught in the pitfall traps. All these species live in wood mould and probably move mainly on its surface. Ranius and Jansson (2000) found that several species associated with tree hollows (including red-listed hollowspecialist species such as Osmoderma eremita and Elater ferrugineus) were mainly caught with pitfall traps.
Previous trap comparisons have usually not evaluated time and other practical aspects at different stages of sampling. Alinvi et al. (2007) compared efficiency among three substantially different sampling methods by ranking their material costs, construction time and time spent sampling, sorting and identifying the samples. From these points of view, they considered window traps the least efficient, bark sampling intermediate and eclectors the most efficient method. Window traps were ranked the lowest on time spent 


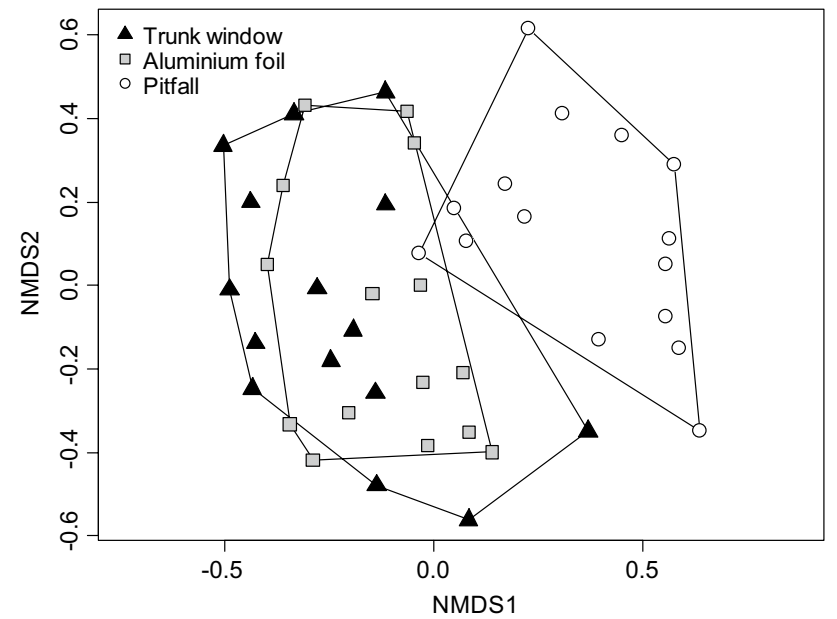

Fig. 4 Two-dimensional NMDS ordination of saproxylic beetle assemblage in the three trap types. The significance level of the distance (using Bray-Curtis dissimilarity index) of species assemblages is $\mathrm{p}<0.001$

Table 5 Average sample weights, time spent separating insects from the samples and numbers of saproxylic species and individuals in the different trap types

\begin{tabular}{lcccrc}
\hline Sample variables & TW & AF & PF & \multicolumn{2}{c}{$\begin{array}{l}\text { Kruskal-Wal- } \\
\text { lis }\end{array}$} \\
\cline { 5 - 7 } & & & & \multicolumn{1}{c}{$\mathrm{X}^{2}$} & \multicolumn{1}{c}{$p$} \\
\hline Weight (g) & $22 \mathbf{a}$ & $24 \mathbf{a}$ & $14 \mathbf{b}$ & $\mathbf{9 . 6}$ & $\mathbf{0 . 0 0 8}$ \\
Time (min) & $41 \mathbf{a}$ & $49 \mathbf{a}$ & $26 \mathbf{b}$ & $\mathbf{2 4 . 6}$ & $\mathbf{0 . 0 0 0}$ \\
Time(min)/weight(g) & 2.3 & 2.6 & 2.5 & 2.8 & 0.247 \\
No of saproxylic beetle species & & & & \\
In a sample & $3.8 \mathbf{a}$ & $3.3 \mathbf{a}$ & $1.9 \mathbf{b}$ & $\mathbf{1 7 . 1}$ & $\mathbf{0 . 0 0 0}$ \\
Per gram & 0.21 & 0.20 & 0.15 & 4.6 & 0.099 \\
Per minute & 0.14 & 0.10 & 0.08 & 2.5 & 0.287 \\
No of saproxylic beetle individuals & & & & \\
In a sample & $14.5 \mathbf{a}$ & $9.3 \mathbf{a}$ & $3.5 \mathbf{b}$ & $\mathbf{1 6 . 2}$ & $\mathbf{0 . 0 0 0}$ \\
Per gram & $0.68 \mathbf{a}$ & $0.50 \mathbf{a b}$ & $0.26 \mathbf{b}$ & $\mathbf{9 . 3}$ & $\mathbf{0 . 0 0 9}$ \\
Per minute & $0.40 \mathbf{a}$ & $0.25 \mathbf{a b}$ & $0.14 \mathbf{b}$ & $\mathbf{7 . 0}$ & $\mathbf{0 . 0 3 0}$ \\
\hline
\end{tabular}

Results of the Kruskal-Wallis test are given. Significant $(p \leq 0.05)$ differences between trap types (Nemenyi post hoc test) are indicated in bold and with different letters

Number of samples $\mathrm{n}=297$

$T W$ trunk window trap, $A F$ aluminium foil trap, $P F$ pitfall trap

sorting samples and on species determination in the laboratory. One contributing factor to this was the large number of non-target beetle individuals caught using window traps.

All the trap types used in our study are very easy to make and have low material costs. Furthermore, aluminium foil and pitfall traps can be bought from any retail store selling household goods and are immediately ready to use. The construction of one trunk window trap took ca. ten minutes.
As the cost of all the trap types was so low, the time spent on other work stages, such as work conducted in the laboratory, became more relevant in the trap type comparisons.

The trunk window trap was the most efficient trap type in our study, when evaluated based on saproxylic species or individuals per minute of sorting time. The quantity of wood mould in the samples had a considerable effect on handling time. Separating insects from samples with large wood mould quantities could take several hours. However, large samples also contained, on average, more individuals and species than small samples. Therefore, the number of saproxylic species recorded per unit time did not depend significantly on sample weight. The average handling time of one sample was approximately $40 \mathrm{~min}$. Handling time of the lightest samples was ca. five minutes. A 10-gram weight increase increased handling time by approximately $15 \mathrm{~min}$. In comparison, when the number of beetle individuals increased by 10 , handling time only increased by ca. three minutes.

Overall, sorting insects from the samples was the most time-consuming part of data collection in our study. It took more time than the fieldwork and beetle material identification combined. This means that any measure reducing the quantity of wood mould in the traps, without simultaneously remarkably reducing the number of beetles caught, will increase the cost-efficiency of sampling inside hollows. One possible solution could be a roof set up above the trap placed on the inner wall of a hollow. However, this may also reduce the beetle catch. Although our decision to place traps inside the cavities increased the amount of wood mould and thus the handling time of the samples in our study, it probably decreased the number of non-target species in the samples and the time spent on their handling and identification in the laboratory. The proportion of non-saproxylic individuals was approximately $10 \%$ of the total number of individuals in both trunk window and aluminium foil traps. None of the previous studies concerning saproxylic beetles in hollow trees have included non-saproxylics. However, other studies which have used trunk window traps to sample saproxylic beetles have reported somewhat more non-saproxylics than what was found in this study (Hyvärinen et al. 2006; Sverdrup-Thygeson and Birkemoe 2009). For example Sverdrup-Thygeson and Birkemoe (2009) caught 13-29\% of non-saproxylic individuals on trunk window traps placed on aspen in Norway. Even if non-target (non-saproxylic) species are not identified to species level, at least some will be sorted out from the samples, which would increase the time spent on each sample (see Alinvi et al. 2007).

We lost 14 samples (one trap $\times$ one sampling period), i.e. traps lost during the sampling period due to vandalism or animal activity in the cavities. This means that only approximately $3 \%$ of the full trapping effort was completely lost. In this respect, the sampling was successful. However, the 
Fig. 5 Relation between sample $(n=297)$ weight and the time spent separating insects from the samples in a laboratory (a) and the number of saproxylic species found in the samples per minute (b). The three trap types are indicated with different symbols
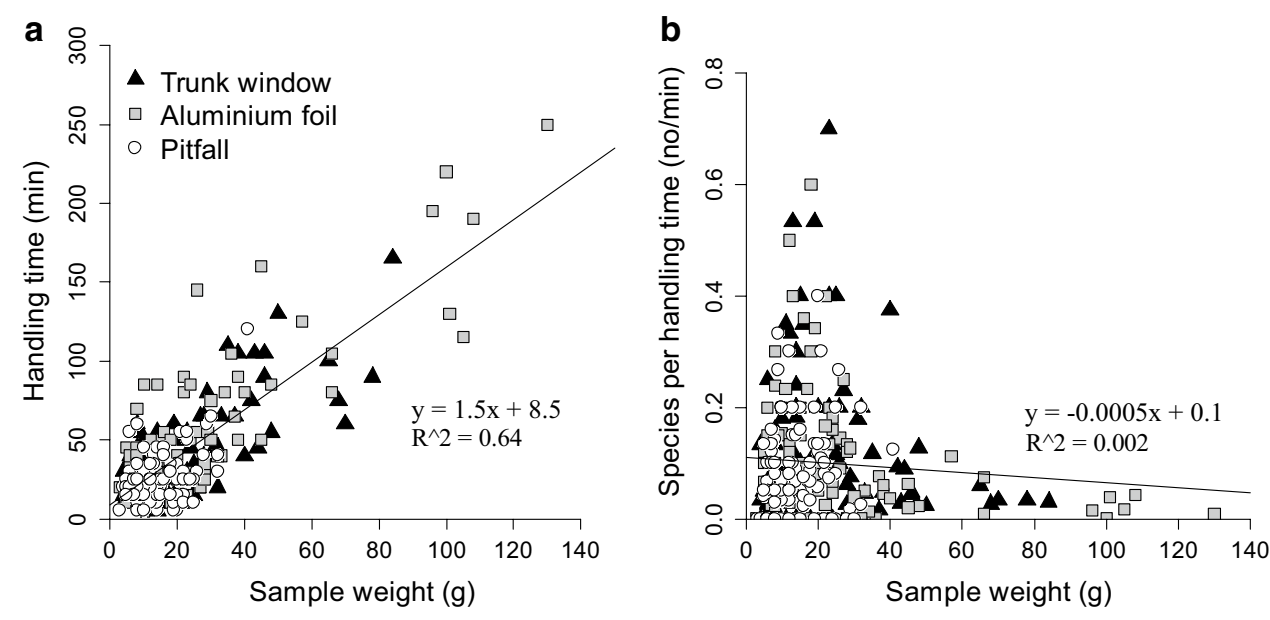

number of empty samples was much larger ( $>60)$, because the traps had dried out, had filled with wood mould or had dropped during a sampling period. We cannot rule out that trap failure also in some of these cases could be due to human interference. Trap failure is a part of trap type efficiency, as the trap design itself may have affected it. More visible traps may be less efficient in urban environments, because of the potentially high risk of losing samples during a trapping period. Even rare events, such as losing most traps during a certain trapping period or some traps during most periods, may jeopardize data usability for the specific study questions that they were designed for. This risk needs to be evaluated based on its probability multiplied by the resulting costs. In this study, we did not use visible traps set outside the hollows, thus the risk of losing samples due to intervention could not be estimated.

However, the probability of losing traps may be smaller than expected. Horak (2011) used ten large trunk window traps attached to dead trees to study saproxylic beetles in an urban forest in the Czech Republic. Contrary to expectations, no traps were removed or damaged by citizens during the five-month trapping period. Similarly, Clarin et al. (2014) observed human interference on only $15 \%$ of dummy scientific equipment in urban areas with semi-hidden conditions.

\section{Saproxylic beetles in hollow urban trees}

Although the main aim of our study was methodological, species richness in hollow urban trees is also interesting. Our results may be compared, at least indicatively, to previous studies in cases where the study effort has been approximately similar regarding the number of trees studied or the number of individuals caught. Our study included fifteen sampling trees and we caught a total of ca. 4000 saproxylic individuals representing 131 species. Jonsell (2004) studied eight hollow limes in southern Sweden, half of which were located in a rural manor park and half in an area of grazed woodland. A total of 647 individuals of 67 saproxylic beetle species were found in the manor park, and 1011 individuals of 97 species in the grazed woodland. Ranius and Jansson (2002) studied 90 hollow oaks in southern Sweden using window traps, pitfall traps and wood mould sampling. They found 125 species; however, they did not identify Aderidae, Corticariini, Dasytinae, Nitidulidae, Ptiliidae, Salpingidae, Scolytinae, Scraptidae or certain Staphylinidae. If species belonging to these families are also excluded from our data, the comparable number of species is 113 . Finally, Quinto et al. (2013) studied 63 hollow oaks and ashes in Mediterranean woodlands in Spain using window, eclector and tube traps. They caught 5084 saproxylic beetle individuals belonging to 206 species. These examples indicate that hollow trees in urban parks can host equally rich fauna as similar trees in more natural woodlands.

\section{Conclusions}

Our findings support the importance of urban old hollow trees to saproxylic beetle communities. Five of the species we found are classified as near threatened (NT) in Finland, and many of the species caught (including the three most abundant species in the material) are specialized on hollow trees. The number of species between the sampling trees differed notably, which indicates species to be dependent on the characteristics of the trees. In Finland, large hollow lindens and oaks exist mainly on hemiboreal zone in the southwestern coastal part of the country, where the largest cities are also located and the percentage of urbanized area is the highest. This further highlights the importance of urban green areas to old large hollow trees and the species dependent on them.

We conclude that saproxylic beetle fauna living in hollows can be efficiently sampled with small trunk window traps or containers without windows placed on the inner 
walls of hollows. If the purpose of a survey is to compile as comprehensive list of species present as possible, then these "trunk traps" should be complemented with pitfall traps.

Our results emphasizes the importance of optimization of trapping methods when sampling saproxylic species assemblages in hollow urban trees. In addition, our results have practical implications for future studies and conservation of saproxylic communities in urban trees. More detailed and local information is needed to benefit practical conservation of saproxylic species in urban areas. Information would be especially usable for cities and organizations which are responsible for green area maintenance.

Acknowledgements Open access funding provided by University of Helsinki including Helsinki University Central Hospital. We would like to thank Hannu Rita, Jyrki Muona, Dmitry Schigel and Riikka Linnakoski for valuable comments on the manuscript, and H. Rita, Anne-Maarit Hekkala and Tuula Kantola for advice with the statistical analyses. We are grateful to Meeri Karvinen for field and lab assistance and to Pirjo Appelgren and Stella Thompson for lab assistance. The city of Helsinki provided valuable information and support for our study. This study is part of a larger project investigating the importance of hollow urban trees to the diversity of saproxylic invertebrates. The project has been financially supported by the following foundations: Jenny and Antti Wihuri Foundation, Niemi Foundation, Otto A. Malm Foundation, E. J. Sariola Foundation, Societas pro Fauna et Flora Fennica, Oscar Öflunds Stiftelse and The Finnish Foundation for Nature Conservation.

\section{Compliance with ethical standards}

Conflict of interest The authors declare that they have no conflicts of interest.

Ethical approval Our study was conducted in compliance with the Finnish nature conservation legislation, and all necessary permissions were obtained from landowners. No protected species were caught or otherwise harmed.

Open Access This article is distributed under the terms of the Creative Commons Attribution 4.0 International License (http://creativeco mmons.org/licenses/by/4.0/), which permits unrestricted use, distribution, and reproduction in any medium, provided you give appropriate credit to the original author(s) and the source, provide a link to the Creative Commons license, and indicate if changes were made.

\section{References}

Ahti T, Hämet-Ahti L, Jalas J (1968) Vegetation zones and their sections in northwestern Europe. Ann Bot Fenn 5:169-211

Alexander KNA (1998) The links between forest history and biodiversity: the invertebrate fauna of ancient pasture woodlands in Britain and its conservation. In: Kirby KJ, Watkins C (eds) The ecological history of European forests. CAB International, Wallingford, pp 73-80

Alexander KNA (2008) Tree biology and saproxylic Coleoptera: issues of definitions and conservation language. Rev Ecol 63(Suppl 10):9-13
Alinvi O, Ball JP, Danell K, Hjältén J, Pettersson RB (2007) Sampling saproxylic beetle assemblages in dead wood logs: comparing window and eclector traps to traditional bark sieving and a refinement. J Insect Conserv 11:99-112

Andersson H (1999) Rödlistade eller sällsynta evertebrater knutna till ihåliga, murkna eller savande träd samt trädsvampar i Lunds stad. [Red-listed or rare invertebrates associated with hollow, rotting, or sapping trees or polypores in the town of Lund.]. Entomol Tidskr 120:169-183

Biström O, Kaila L, Kullberg J (2000) Herttoniemen kartanopuiston puukovakuoriaisista (Coleoptera). [Survey of the tree-living Coleoptera in Herttoniemi manor-park. southern Finland]. Sahlbergia 5:14-20

Bouget C, Nageleisen M-L (2009) Forest insect studies: methods and techniques. Key considerations for standardization. Les Dossiers Forestiers no19. French Office National des Forêts, Paris

Bouget C, Brustel H, Brin A, Noblecourt T (2008) Sampling saproxylic beetles with window flight traps: methodological insights. Rev Ecol 63(Suppl 10):21-32

Bußler H, Müller J (2014) Vacuum cleaning for conservationists: a new method for inventory of Osmoderma eremita (Scop., 1763) (Coleoptera: Scarabaeidae) and other inhabitants of hollow trees in Natura 2000 areas. J Insect Conserv 13:355-359

Clarin B-M, Bitzilekis E, Siemers BM, Goerlitz HR (2014) Personal messages reduce vandalism and theft of unattended scientific equipment. Methods Ecol Evol 5:125-131

Denton J, Chandler P (2005) Rotherfield Park, North Hampshire: an important site for saproxylic Coleoptera, Diptera and other insects. Br J Entomol Nat Hist 18:9-15

Dubois GF, Vignon V, Delettre YR, Rantier Y, Vernon P, Burel F (2009) Factors affecting the occurrence of the endangered saproxylic beetle Osmoderma eremita (Scopoli, 1763) (Coleoptera: Cetoniidae) in an agricultural landscape. Landsc Urban Plan 91:152-159

Franc V (1997) Old trees in urban environments. Refugia for rare and endangered beetles (Coleoptera). Acta Univ Carolinae Biol 41:273-283

Gibbons P, Lindenmayer DB, Fischer J, Manning AD, Weinberg A, Seddon J, Ryan P, Barrets G (2008) The future of scattered trees in agricultural landscapes. Conserv Biol 22:1309-1319

Gouix N, Brustel H (2011) Emergence trap, a new method to survey Limoniscus violaceus (Coleoptera: Elateridae) from hollow trees. Biodiv Conserv 21:421-436

Harding PT, Alexander KNA (1994) The use of saproxylic invertebrates in the selection and evaluation of areas of relic forest in pasture-woodlands. Br J Entomol Nat Hist 7(Suppl 1):21-26

Hartel T, Dorresteijn I, Klein C, Máthé O, Moga CI, Öllerer K, Roellig M, von Wehrden H, Fischer J (2013) Wood-pastures in a traditional rural region of Eastern Europe: Characteristics, management and status. Biol Conserv 166:267-275

Hedin J, Ranius T, Nilsson SG, Smith HG (2008) Restricted dispersal in a flying beetle assessed by telemetry. Biodivers Conserv 17:675-684

Horák J (2011) Response of saproxylic beetles to tree species composition in a secondary urban forest area. Urban For Urban Green 10:213-222

Hyvärinen E, Kouki J, Martikainen P (2006) A comparison of three trapping methods used to survey forest-dwelling Coleoptera. Eur J Entomol 103:397-407

Jansson N, Bergman K-O, Jonsell M, Milberg P (2009) An indicator system for identification of sites of high conservation value for saproxylic oak (Quercus spp.) beetles in southern Sweden. J Insect Conserv 13:399-412

Jonsell M (2004) Old park trees: a highly desirable resource for both history and beetle diversity. J Arboriculture 30:238-244 
Jonsell M (2012) Old park trees as habitat for saproxylic beetle species. Biodivers Conserv 21:619-642

Kaila L (1993) A new method for collecting quantitative samples of insects associated with decaying wood or wood fungi. Entomol Fenn 4:21-23

Koch K (1989-1995) Die Käfer Mitteleuropas, Ökologie (Bde. E1E8). Goecke \& Evers Verlag, Krefeld

Leather S (ed) (2005) Insect sampling in forest ecosystems. Blackwell Publishing, Oxford

Lindenmayer DB, Laurance WF, Franklin JF (2012) Global decline in large old trees. Science 338:1305-1306

Lindhe A, Lindelöw A (2004) Cut high stumps of spruce, birch, aspen and oak as breeding substrates for saproxylic beetles. For Ecol Manage 203:1-20

Lõhmus K, Liira J (2013) Old rural parks support higher biodiversity than forest remnants. Basic Appl Ecol 14:165-173

McCune B, Grace JB (2002) MRPP (Multi-response Permutation Procedures) and related techniques. In: Analysis of ecological communities. MjM Software Design, Gleneden Beach, Oregon, pp 188-197

Nieto A, Alexander KNA (2010) European red list of saproxylic beetles. Publications Office of the European Union, Luxembourg

Nilsson SG, Baranowski R (1997) Habitat predictability and the occurrence of wood beetles in old-growth beech forests. Ecography 20:491-498

Nowak DJ, Noble MH, Sisinni SM, Dwyer JF (2001) Assessing the US urban forest resource. J For 99:37-42

Økland B (1996) A comparison of three methods of trapping saproxylic beetles. Eur J Entomol 93:195-209

Oleksa A, Ulrich W, Gawroński R (2006) Occurrence of the marbled rose-chafer (Protaetia lugubris Herbst, Coleotera, Cetoniidae) in rural avenues in northern Poland. J Insect Conserv 10:241-247

Palm T (1951) Die Holz- und Rinden-Käfer der nordschwedischen Laubbäume. Meddelanden Statens Skogsforskningsinstitut No 44:242 pp

Palm T (1959) Die Holz- und Rinden-Käfer der süd- und mittelschwedischen Laubbäume. Opuscula Entomol XVI 374

Quinto J, de los Angeles Marcos-Garcia M, Brustel H, Galante E, Mico E (2013) Effectiveness of three sampling methods to survey saproxylic beetle assemblages in Mediterranean woodland. J Insect Conserv 17:765-776
R Development Core Team (2008) R: a language and environment for statistical computing. R Foundation for Statistical Computing

Ranius T, Jansson N (2002) A comparison of three methods to survey saproxylic beetles in hollow oaks. Biodivers Conserv 11:1759-1771

Rassi P, Hyvärinen E, Juslén A, Mannerkoski I (eds) (2010) The 2010 Red List of Finnish species. Ministry of the Environment, Helsinki

Rassi P, Karjalainen S, Clayhills T et al (2015) Kovakuoriaisten maakuntaluettelo 2015 [Provincial List of Finnish Coleoptera 2015]. Sahlbergia 21(Suppl 1):1-164

Schwarze FWMR, Engels J, Mattheck C (2000) Fungal strategies of decay in trees. Springer, Berlin

Siitonen J (1994) Decaying wood and saproxylic Coleoptera in two old spruce forests: a comparison based on two sampling methods. Ann Zool Fenn 31:89-95

Siitonen J (2012a) Microhabitats. In: Stokland J, Jonsson B-G, Siitonen J Biodiversity in dead wood. Cambridge University Press, Cambridge, pp 150-182

Siitonen J (2012b) Dead wood in agricultural and urban habitats. In: Stokland J, Jonsson B-G, Siitonen J Biodiversity in dead wood. Cambridge University Press, Cambridge, pp 380-401

Sjöman H, Östberg J, Bühler O (2012) Diversity and distribution of the urban tree population in ten major Nordic cities. Urban For Urban Green 11:31-39

Speight MCD (1989) Saproxylic invertebrates and their conservation. Council of Europe, Publications and Documents Division, Strasbourg

Sverdrup-Thygeson A, Birkemoe T (2009) What window traps can tell us: effect of placement, forest openness and beetle reproduction in retention trees. J Insect Conserv 13:183-191

Sverdrup-Thygeson A, Skarpaas O, Ødegaard F (2010) Hollow oaks and beetle conservation: the significance of the surroundings. Biodivers Conserv 19:837-852

Waite EM, Closs G, Van Heezik Y, Berry C, Dickinson K (2012) Arboreal arthropod sampling methods for urban trees. J Insect Conserv 16:931-939

Wikars L, Sahlin E, Ranius T (2005) A comparison of three methods to estimate species richness of saproxylic beetles (Coleoptera) in logs and high stumps of Norway spruce. Can Entomol 137:304-324 